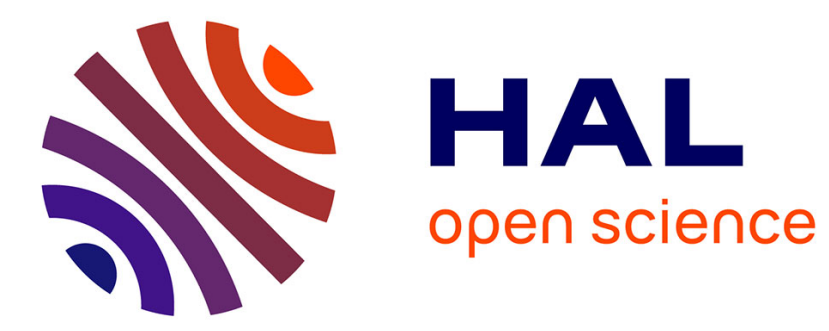

\title{
High pressure spectroscopy of heavily doped ruby
}

\author{
D. Galanciak, S. Legowski, H. Meczynska, M. Grinberg
}

\section{To cite this version:}

D. Galanciak, S. Legowski, H. Meczynska, M. Grinberg. High pressure spectroscopy of heavily doped ruby. Journal de Physique IV Proceedings, 1994, 04 (C4), pp.C4-565-C4-568. 10.1051/jp4:19944136 . jpa-00252588

\section{HAL Id: jpa-00252588 https://hal.science/jpa-00252588}

Submitted on 1 Jan 1994

HAL is a multi-disciplinary open access archive for the deposit and dissemination of scientific research documents, whether they are published or not. The documents may come from teaching and research institutions in France or abroad, or from public or private research centers.
L'archive ouverte pluridisciplinaire HAL, est destinée au dépôt et à la diffusion de documents scientifiques de niveau recherche, publiés ou non, émanant des établissements d'enseignement et de recherche français ou étrangers, des laboratoires publics ou privés. 


\title{
High pressure spectroscopy of heavily doped ruby
}

\author{
D. GALANCIAK, S. ŁEGOWSKI, H. MȨCZYŃSKA and M. GRINBERG \\ Institute of Physics, N. Copernicus University, Grudziądzka 5/7, PL87-100 Tonun, Poland
}

\begin{abstract}
Measurements include studies of effect of hydrostatic pressure, up to $80 \mathrm{kbar}$, on fluorescence spectra of ruby, especially the pressure dependence of the energy of the lines related to fluorescence of paired $\mathrm{Cr}^{3+}$ ions. We have considered the high pressure spectroscopy experiments as effective tool for identification of the lines and investigation of the exchange interaction.
\end{abstract}

At low concentration of $\mathrm{Cr}^{3+}$ ions ( about $0.1 \mathrm{wt} \%$ ) the ruby fluorescence is dominated by two strong zero-phonon lines $\left(R_{1}\right.$ and $\left.R_{2}\right)$ related to ${ }^{2} \mathrm{E} \rightarrow{ }^{4} \mathrm{~A}_{2}$ transitions in single $\mathrm{Cr}^{3+}$ ions, whereas for chromium concentration above critical yalue ( 0.4 wt\%) additional sharp lines from exchange -coupled the $\mathrm{Cr}^{3+}$ pairs appear. Also a long wave broad band emission, due to existence of $\mathrm{Cr}^{3+}$ ions clusters is detected [1]. Our spectral data have been obtained using optical multichannel analyzer. Excitation was provided by the $488 \mathrm{~nm}$ line of $\mathrm{Ar}$ laser at room temperature. A high pressure was applied with sapphire anvils [2], up to $80 \mathrm{kbar}$. As the pressure medium 4:1 methanol - ethanol mixture was used. We have observed the $R_{1}, R_{2}, N_{1}, N_{2}$ lines and also several others related

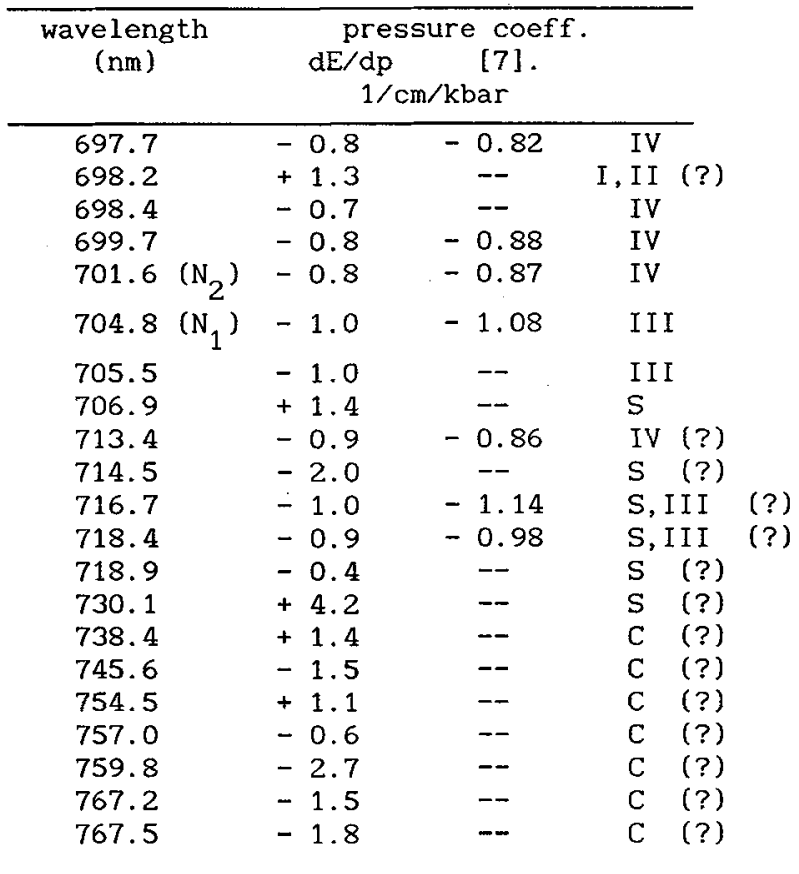

Table 1. Wavelength and pressure coefficients

of individual spectral

lines in ruby. In column four possible assignation of the lines is presented. III and IV correspond to the third and fourth nearest neighbor pair, respectively, $S$ corresponds to sideband, $\mathrm{C}$ corresponds to clusters. 
to pairs of $\mathrm{Cr}^{3+}$ ions, $\mathrm{Cr}$ clusters and the phonons sideband. We have determined pressure coefficients of the lines ( see Tab.1).

We have considered that emission related to the pairs of $\mathrm{Cr}^{3+}$ ions in $\mathrm{Al}_{2} \mathrm{O}_{3}$ is due to the radiative transitions between particular components of the excited state $\left.\right|^{2} E(A)>1^{4} A_{2}(B)>$ and the ground state $1^{4} A_{2}(A)>1{ }^{4} A_{2}(B)>$ of energies [3], [4] :

$E_{e}=E_{0}\left({ }^{2} E\right)+K_{e}\left(r_{A B}\right)+\Theta_{e}\left(r_{A B}\right)+0.5 J e_{e}\left(r_{A B}\right)\left[S_{e}\left(S_{e}+1\right)-9 / 2\right]$

and

$E_{g}=E_{0}\left({ }^{4} A_{2}\right)+K_{g}\left(r_{A B}\right)+\Theta_{g}\left(r_{A B}\right)+0.5 J_{g}\left(r_{A B}\right)\left[S_{g}\left(S_{g}+1\right)-15 / 2\right]$,

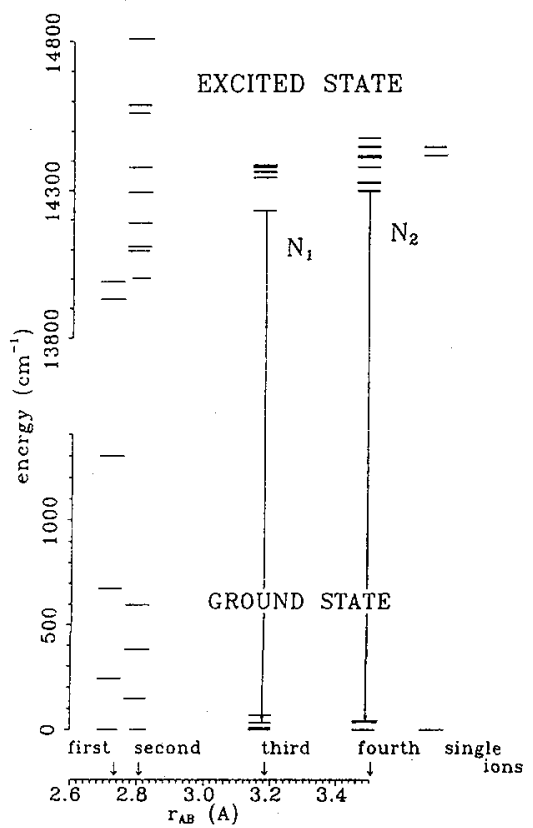

Fig. $3+$ Energetic structure of $\mathrm{Cr}^{3+}$ ions pairs in ruby. respectively. In formulas (1) and (2) $K_{i}$ and $J_{i}(i=e, g)$ correspond to theCoulomb and exchange interaction, respectively, $S_{i}$ is the resulting spins ( for the ground state $s_{g}=0,1,2,3$ and for the excited state $\left.S_{e}=1,2\right), \quad \Theta_{i}$ is additional energy related to the crystal field of trigonal symmetry, $\mathrm{r}_{\mathrm{AB}}$ is interionic distance. The energetic structure of the ground state is well described by exchange interaction, whereas the energetic structure of the excited state is rather complicated [5], [1] ( see also Fig. 1).

Since the Coulomb, trigonal field and exchange integrals depend on the distance between the paired ions they depend also on pressure and therefore give contributions to the pressure coefficient of the emission line. For analysis of our fluorescence spectra we have considered that the energy of the individual line is defined by $\mathrm{E}=$ $E_{e}-E_{g}$. Hence the pressure coefficient of the line, $\mathrm{dE} / \mathrm{dp}$ is given by;

$$
\begin{aligned}
& d E / d p=d \Delta_{0} / d p+d K\left(r_{A B}\right) / d p+d \Theta\left(r_{A B}\right) / d p+0.5 d J_{e}\left(r_{A B}\right) / d p\left[S_{e}\left(S_{e}+1\right)\right. \\
& -9 / 2]-0.5 d J_{g}\left(r_{A B}\right) / d p\left[S_{g}\left(S_{g}+1\right)-15 / 2\right],
\end{aligned}
$$

where $d \Delta_{0} / d p$ is pressure coefficient of the ${ }^{2} E \rightarrow{ }^{4} A_{2}$ transition in a 
free ion $\left(\mathrm{d} \Delta_{0} / \mathrm{dp}=-0.76 \mathrm{~cm}^{-1} / \mathrm{kbar}\right), \mathrm{K}\left(\mathrm{r}_{\mathrm{AB}}\right)$ is equal to $\mathrm{K}_{\mathrm{e}}-\mathrm{K}_{\mathrm{g}}$ and $\Theta\left(r_{A B}\right)=\Theta_{e}-\Theta_{g}$. One should notice that since we measure energies of transitions for the pairs characterized by well defined interionic distance (first, second, third, fourth, etc. nearest neighbors) the quantities; $\quad d K\left(r_{A B}\right) / d p, d J_{e}\left(r_{A B}\right) / d p$ and $d J_{g}\left(r_{A B}\right) / d p$ can be estimated independently, knowing pressure dependence of the lattice parameters of $\mathrm{Al}_{2} \mathrm{O}_{3}$, and the values of $\mathrm{J}_{\mathrm{e}}, \mathrm{J}_{\mathrm{g}}, \mathrm{K}$ and $\Theta$ for various pairs. Measured compressibility for ruby, $1.36-1.22 * 10^{-4} \mathrm{kbar}^{-1}[6]$, allows to determine $\mathrm{dr}_{\mathrm{AB}} / \mathrm{dp}$ for any pair.

For analysis we have considered the energetic structure of the pairs as presented in Fig. 1. [1]. One can calculate the dependence of the exchange and Coulomb integrals: $\mathrm{J}_{\mathrm{g}}$ and $\mathrm{K}$ on $\mathrm{r}_{\mathrm{AB}}$ (see Fig. 2).

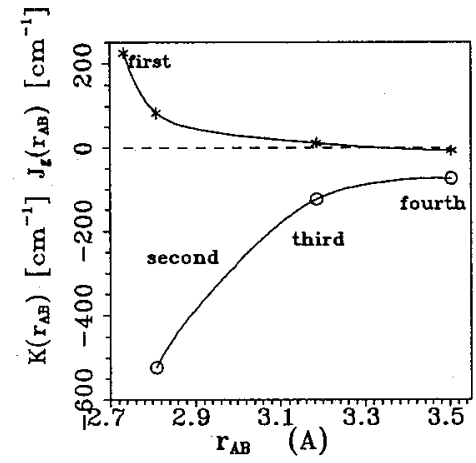

Fig. 2. The Coulomb and exchange interaction of $\mathrm{Cr}^{3+}$ pairs in ruby. Circles and asterisks correspond to the values of $K\left(r_{A B}\right)$ and $J_{g}\left(r_{A B}\right)$, respectively, for the first, second, third and fourth nearest neighbor pairs.

For obtaining $\mathrm{K}\left(\mathrm{r}_{\mathrm{AB}}\right)$ we have calculated the centers of gravity of the ground and excited states using the energies presented in Fig. 1 , assuming that each component of the excited state has the same degeneracy. The results are presented in Fig. 2. One estimates the quantities: $d K\left(r_{A B}\right) / d p$ and $d_{g}\left(r_{A B}\right) / d p$ for individual pairs ( see Table 2.)

\begin{tabular}{ccccc}
\hline $\mathrm{cm}^{-1} / \mathrm{kbar}$ & I & II & III & IV \\
\hline $\mathrm{d} \mathrm{K}\left(\mathrm{r}_{\mathrm{AB}}\right) / \mathrm{dp}$ & $?$ & -0.5 & -0.25 & $\sim-0.1$ \\
$\mathrm{~d} \mathrm{~J} \mathrm{~J}_{\mathrm{g}}\left(\mathrm{r}_{\mathrm{AB}}\right) / \mathrm{dp}$ & $>0.3$ & $\sim 0.18$ & 0.05 & $\sim 0.0$ \\
\hline
\end{tabular}

Table 2. Pressure coefficients of the exchange and Coulomb integrals for the first, second, third and fourth nearest neighbor $\mathrm{Cr}^{3+}$ pairs.

One can see that for all cases the Coulomb interaction depends much stronger on pressure than exchange interaction. Unfortunately, since we do not know the exact interpretation of the structure of the excited states, it is impossibly to estimate the quantities $\mathrm{d} \Theta / \mathrm{dp}$ and $\mathrm{dJ} / \mathrm{dp}$. Nevertheless because each fluorescence line can be related to respective pair we can test whether $d \Theta / d p$ and $d J_{e} / d p$ really influence the spectra. 
We have performed detailed calculations for $\mathrm{N}_{1}$ and $\mathrm{N}_{2}$ lines assuming that they correspond to transitions from thermalized levels of the excited state, to $\mathrm{S}=2$ component of the ground state in third neighbor pair $\left(\mathrm{N}_{1}\right)$, and to the $S=1$ component of the ground state in fourth nearest neighbor pair $\left(\mathrm{N}_{2}\right)$. The second assumption was that the exchange coupling in the excited state is ferromagnetic and antiferromagnetic in the case of fourth and third nearest neighbor pairs, respectively. Using formula (3) and data from Table 2 . we have obtained

$\mathrm{dN}_{1} / \mathrm{dp}=-1.05+\mathrm{d} \Theta\left(\mathrm{r}_{\mathrm{AB}}\right) / \mathrm{dp}+\mathrm{dJ}_{\mathrm{e}}\left(\mathrm{r}_{\mathrm{AB}}\right) / \mathrm{dp} 3 / 4 \mathrm{~cm}^{-1} / \mathrm{kbar}$
$\mathrm{dN}_{2} / \mathrm{dp}=-0.86+\mathrm{d} \Theta\left(\mathrm{r}_{\mathrm{AB}}\right) / \mathrm{dp}-\mathrm{dJ}_{\mathrm{e}}\left(\mathrm{r}_{\mathrm{AB}}\right) / \mathrm{dp} 5 / 4 \mathrm{~cm}^{-1} / \mathrm{kbar}$.

One can see that in both cases the calculated pressure coefficients are the same as experimental (see Table 1.) under a condition that contributions from trigonal field and exchange interaction in the excited state are zero or compensate each other. In fact, in the case of the third and fourth nearest neighbor pairs the exchange interaction can be weak and therefore does not influence much the pressure coefficient. Also the role of the changes of the trigonal field with pressure for longer distance pairs is rather negligible. The experimental data seems to confirm this prediction, since all spectral lines identified as related to third and fourth nearest neighbor pairs are characterized by pressure coefficients of the order of $-0.7 \sim-1 \mathrm{~cm}^{-1} / \mathrm{kbar}$.

However, one should notice that it can not concern the first and second nearest neighbor pairs. Actually we have observed the lines with positive pressure coefficients ( see Table 1). Part of them is related to phonon sideband of the spectrum, nevertheless our model predicts also the ${ }_{+}$possibility of positive pressure coefficients of lines related to $\mathrm{Cr}^{3+}$ pairs systems. Relation (3) shows that positive contributions to the pressure coefficients of the fluorescence lines are related to;

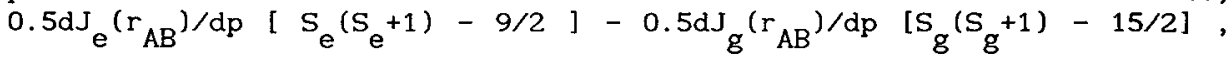
under conditions that $\mathrm{S}_{\mathrm{e}}=2$ and $\mathrm{S}_{\mathrm{g}} \leq 2$. Especially for close pairs ( the first or second nearest neighbor) this quantity can dominate.

Acknowledgements

This work has bee supported by Grant no; $554-F$ of $N$. Copernicus University

\section{References}

[1] R.C. Powell B. DiBartolo, phys. stat. sol. 10, 315 (1972).

[2] A. Jayaraman, Rev. Mod. Phys. 55,65 (1983).

[3] A. H. Morrish, The Physical Principles of Magnetism, ( J. Willey , New York (1965)).

[4] A. E. Nikiforov and V.I. Cherepanov, phys. stat. sol. 14, 391 (1966). [5] R. C. Powell, B. DiBartolo, B. Birang, and C. S. Naiman, in Optical Properties of Ions in Crystals, E. D. by Crosswhite, H. W. Moss, Interscience Publishers New York (1967) p. 207.

[6] L.W. Finger, R.M. Hazen J. Appl. Phys. 49, 5823 (1979).

[7] L.D. Merkle, I.L. Spain, R.C. Powell, J. Phys. C 14, 2027 ( 1981 ). 